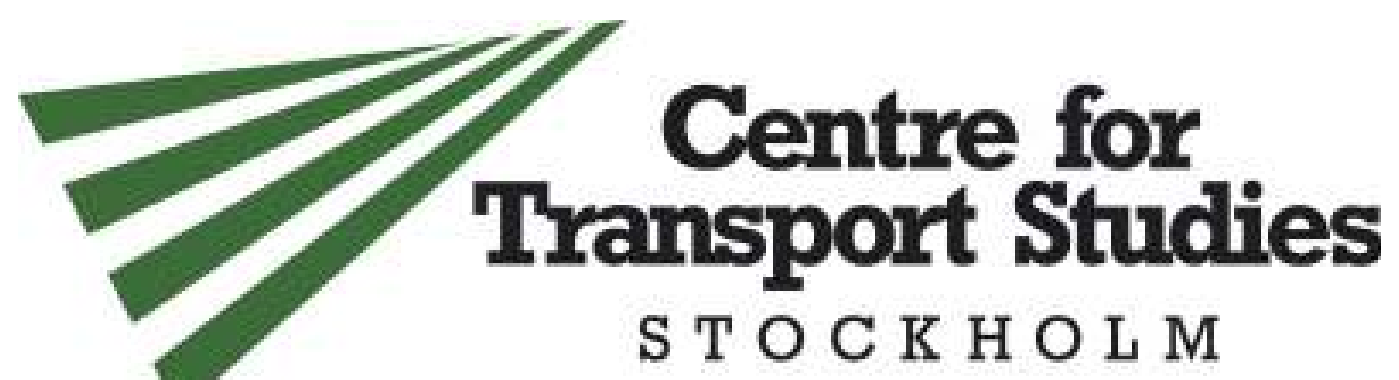

\title{
Comparing rail passengers' travel time use in Great Britain between 2004 and 2010
}

\author{
Glenn Lyons - University of the West of England, Bristol, UK \\ Juliet Jain - University of the West of England, Bristol, UK \\ Yusak O. Susilo - Royal Institute of Technology (KTH) \\ Steve Atkins - University of the West of England, Bristol, UK
}

CTS Working Paper 2013:17

\begin{abstract}
This paper provides a unique insight into aspects of stability and change regarding the travel time use of rail passengers in Great Britain between 2004 and 2010. Empirical evidence is presented on how rail passengers spend their time, how worthwhile they consider their time use to be, the extent of advance planning of their time use and how equipped for time use they are in terms of the items they have to hand when they travel. The results reveal a consistent dominance of reading for leisure, window gazing/people watching and working/studying as favoured travel time activities. Over the six year period the availability and use of mobile technologies has increased. Listening to music in particular has doubled in its incidence suggesting an increasing capacity for travellers to personalise the public space of the railway carriage. Most notably the analysis reveals a substantial increase in the proportion of travellers overall making very worthwhile use of their time.
\end{abstract}

Keywords: travel time use; multitasking; rail travel; value of time; mobile technologies

JEL Codes: R40, R42

Centre for Transport Studies

SE-100 44 Stockholm

Sweden

www.cts. kth.se
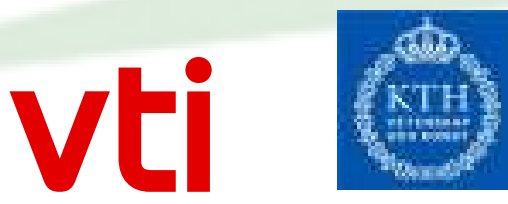



\title{
Comparing rail passengers' travel time use in Great Britain
}

\section{between 2004 and 2010}

\author{
Glenn Lyons ${ }^{* 1}$, Juliet Jain ${ }^{2}$, Yusak Susilo ${ }^{3}$ and Steve Atkins ${ }^{4}$ \\ ${ }^{1,2,4}$ Centre for Transport \& Society, University of the West of England, Bristol \\ ${ }^{3}$ Royal Institute of Technology (KTH), Stockholm, Sweden \\ * Corresponding author: \\ Professor Glenn Lyons, Centre for Transport \& Society, Faculty of Environment and \\ Technology, University of the West of England, Frenchay Campus, Coldharbour Lane, \\ BRISTOL BS16 1QY. United Kingdom. \\ Email Glenn.Lyons@uwe.ac.uk Telephone +44 1173283129
}

Keywords: travel time use; multitasking; rail travel; value of time; mobile technologies

To cite this article: Glenn Lyons, Juliet Jain , Yusak Susilo \& Stephen Atkins (2012): Comparing Rail Passengers' Travel Time Use in Great Britain Between 2004 and 2010, Mobilities, DOI:10.1080/17450101.2012.743221 


\title{
Comparing rail passengers' travel time use in Great Britain between 2004 and 2010
}

\author{
Abstract \\ This paper provides a unique insight into aspects of stability and change regarding the travel \\ time use of rail passengers in Great Britain between 2004 and 2010. Empirical evidence is \\ presented on how rail passengers spend their time, how worthwhile they consider their \\ time use to be, the extent of advance planning of their time use and how equipped for time \\ use they are in terms of the items they have to hand when they travel. The results reveal a \\ consistent dominance of reading for leisure, window gazing/people watching and \\ working/studying as favoured travel time activities. Over the six year period the availability \\ and use of mobile technologies has increased. Listening to music in particular has doubled in \\ its incidence suggesting an increasing capacity for travellers to personalise the public space \\ of the railway carriage. Most notably the analysis reveals a substantial increase in the \\ proportion of travellers overall making very worthwhile use of their time.
}

\section{Introduction}

In recent years there has been a growing discourse and evidence base concerning how people use their time when they travel. This paper represents what we believe to be the first empirical evidence of how people's travel time use is changing over time.

While it may seem peculiar to those scholars engaged in the 'mobility turn' within the social sciences, for many years orthodox thinking in transport planning has identified travel as simply a means to an end. It represents the disutility of time spent to access and participate 
in activities at alternative spatial locations. Slower journeys are seen to reflect a greater cost to the individuals concerned and to society in economic terms. Accordingly, investment in transport infrastructure and services has been justified largely by the prospect of making journeys quicker and 'recovering' wasted travel time such that it can be put to more economically or socially productive use. However, a growing body of research has been exploring the notion that travel is more than a means to an end and in fact can be an end in itself with the prospect of positive utility (or reduced net disutility) derived from how travel time is used (Mokhtarian and Salomon, 2001).

The British research project 'Travel Time Use in the Information Age' proved central in leading a new set of debates that focuses on how travel time is used, what meaning it holds for individuals and what the emerging consequences of the information age might be in terms of mobile devices (Lyons and Urry, 2005). As part of this project, the research team designed a set of questions that were included in the Autumn 2004 wave of the National Rail Passenger Survey (NRPS) and which captured data from 26,221 rail passengers in Great Britain about: how their travel time had been used; what items they had with them; the specific role of new technologies in supporting time use; and how worthwhile the travel time was considered to be (Lyons et al, 2007). The design of the questions was informed by pilot 'in-situ' observations, and research on technology use by mobile workers (see for example: Laurier, 2002; Brown and O'Hara 2003), portable music devices (see for example Du Guy et al, 1997; and Bull, 2000), and historic accounts of rail travel (Schivelbusch, 1980). The survey questions and response data have been of interest to other researchers subsequently in terms of further data analysis (e.g. Kirby et al, 2006) and influencing survey design (e.g. Gripsrud and Hjorthol, 2009). Indeed a number of subsequent studies of rail 
travel time use have emerged, and Russell et al. (2011) compare such studies in developing the design of structured observation approach to study travel time use.

While there continues to be a need for greater understanding of travel time use and its meaning and value, there is also a need for insight into how behaviour might be changing over time. Recent inventions and innovations in portable communication devices have provided individuals with various new ways of spending time while travelling. This paper provides a unique opportunity to examine change over time. The authors secured in the Autumn 2010 National Passenger Survey (NPS) the inclusion of a subset of the questions that were originally asked in the Autumn 2004 survey. The paper thus provides evidence into how travel time use has changed (or not) over a six year period. It should be noted that the survey data captured is cross-sectional in nature - thus consideration of intra-individual change over time that would be afforded by a panel study is not possible. Nevertheless the paper offers unique macro-level comparisons over the time period between cross sections.

There is no specific methodological reason for a six year gap, other than the research team being aware of rapid changes in the field of mobile technologies allied to it seizing the opportunity to once again be able to include questions in this major national survey, coincident with national debate concerning high speed rail. The following illustrates a sense of rapid technological change. Facebook was only launched in February 2004 (a few months before the first survey point) - six years later such social networking is seen to have established a presence as part of rail travel. Tablet PCs became an option some rail travellers in 2010 which did not exist in 2004 - the Amazon Kindle was only launched for the UK in October 2009 and the Apple iPad in May 2010. The research was able to deliver- new 
empirical findings at a time when the UK Government was considering multi-billion pound investment in high speed rail. The economic case for such investment has had to confront the challenge to orthodox thinking in terms of how rail travel time savings can be valued in

the context of (some) passengers making productive use of (some of) their time (DfT, 2011a; DfT 2009). The evidence set out in this paper was submitted in summary form to the House of Commons Transport Committee's inquiry into High Speed Rail and is specifically recognised in its November 2011 Report (Transport Committee, 2011a: 31, 2011b: 231-232, 2011c: 553-555).

The paper is organised as follows. The next section provides a selective review of key insights into travel time use and its meaning and value. The following section introduces the NPS, the specific questions on travel time use and some analytical considerations. The main section of the paper presents an examination of the survey findings and a comparison with the 2004 survey data. The final section of the paper discusses key issues relating to the evolving understanding of travel time use.

Insights into the significance, meaning and value of travel time use

\section{Enacting and experiencing travel time}

Mokhtarian and Salomon have identified three means by which positive utility can be derived from travel: "1. the activities conducted at the destination; 2 . activities that can be conducted while travelling; 3 . the activity of travelling itself" (Mokhtarian and Salomon, 2001: 701). This underlines the need to recognise that travel itself has constructive meaning in people's lives beyond being a means to an end. Jain and Lyons (2008) introduced the 
notion of the gift of travel time that inherently connects the three points identified by Mokhtarian and Salomon. They argued that travellers give their time to co-present events by travelling, and while reciprocation may occur through the social network, the travel time itself may be perceived as a gift by the traveller. Travel time as a gift to oneself as the traveller can be conceptualised as: “1. Transition time - a need for experiencing distance and the opportunity for gearing up to the destination's demands; and 2. Time out - escape from the obligations created through co-presence or fixed space that enable time for a 'backstage' time to be oneself or a specific activity (e.g. reading)" (Jain and Lyons, 2008: 85).

Context shapes the traveller's perception of whether travel time is a gift or not. Here journey duration and experience of time are important factors. Research testing the appeal of the notion of teleportation (Mokhtarian and Salomon, 2001; Jain and Lyons, 2008) reveals a desire amongst travellers for a travel time in excess of zero, in fact around 15-20 minutes for commuting - underlining notions of the gift and positive utility (or less negative utility) of travel time. However, what happens in short train journeys is different to longer ones, as this paper goes on to discuss. Whether short or long, the experience of travel time can vary enormously. Train travel socially embedded clock time through the timetable (Jain, 2006) but time is experienced individually in many ways against this temporal framework. Watts (2008) explores the distinctions and explains how travel time can be stretched or compressed according to the individual's state of mind and activity engagement, which is linked to expectations of what is feasible in a given journey duration.

Watts (2008) has highlighted through ethnographic research the need to recognise that a passenger comprises the person plus their belongings, and points to the distinction between 
the packed and unpacked passenger. She theorised that travel time is crafted through the spatial and temporal deployment of unpacked artefacts (paperwork, book, food, laptop computer, MP3 player, etc.) interspersed with looking out the window, thinking or talking to others. In developing these ideas, Watts and Lyons (2010) designed and applied what they referred to as a 'travel remedy kit', which illustrated how, with conscious consideration of travel time in advance of the journey, an individual could equip themselves both in terms of state of mind and in terms of carried objects to improve their journey experience (the research to develop and apply the kit took place in 2007). Bissell (2008) considers the physical and emotional state of creating comfort when travelling. He likewise utilises the notion of crafting to argue that a psychological sense of comfort is produced through such heterogeneous relationships between personal artefacts and the physical space of the carriage.

How people choose to use the artefacts that they unpack, is culturally dependent. Research from Japan, for instance, demonstrates that it is culturally unacceptable for phone calls to be made in public, therefore communicating with others is mostly by text and/or email on the train (Ohmori and Harata, 2009). Notions of ownership of time may also be significant. Consider, for example, commuting. In the UK this is generally taken to be undertaken in the employee's time rather than the employer's time. Meanwhile in Norway, commuters can discount work conducted while commuting from the hours in the office. This incentive is reflected in higher numbers of individuals working during their commute in Norway than in the UK (Gripsrud and Hjorthol, 2009). 
Travel time use can be considered a form of multitasking since it takes place, by definition, at the same time as an individual is engaged in the activity of travel itself (Kenyon and Lyons, 2007) and the efforts this entails. Such effort may or may not impinge upon how travel time is spent and experienced

Stradling (2006) refers to three different forms of effort: physical, cognitive and affective; and notes a likely reduction in cognitive effort for familiar routes. Affective effort concerns emotions aligned to uncertainty or worry. In their review of literature concerning the daily commute, Lyons and Chatterjee (2008: 193) suggest that "for many commute journeys, cognitive and affective effort will be low - the routine and familiarity allow the individual to enact the journey almost subconsciously or on 'auto-pilot' (even in the face of congestion)". We would infer that less effort devoted to travel itself yields more potential opportunity for the fruitful spending of travel time.

Listening through headphones on the move is very much a late twentieth century phenomena, which has been radically transformed with digital media and the MP3 player (either as a specific technology such as the iPod, or embedded into other mobile technologies, e.g. mobile phones) in the twenty-first century. The MP3 format has simplified and expanded the opportunity to listen to something anywhere (Simun, 2009). MP3 use (and that of the preceding Walkman) enables control over the mobile experience, and elevates the individual out of the mundane into personal and private experiences (Simun, 2009; Bull, 2000). While Bull (2000) focuses on the pleasurable opportunity to listen on the move, with travel time being when people can choose their listening preference rather than negotiating the collective desires of the household, Skånland (2011) considers the use of 
MP3 as a 'coping strategy' in crowded and noisy contexts that benefits individual wellbeing by reducing stress. She suggests that music is often used as a focus to remove the individual from other worrying thoughts or negative feelings or experiences. Not only does the MP3 player provide entertainment, it may also enable commuters to over-ride the stress of being physically proximate to other travellers (and associated conversation/phone noise) creating a psychological distance and making the journey more pleasurable. We suggest music interplays with the concept of time out, raised earlier, in facilitating individual withdrawal from the immediate situation. In one respect (though not all), donning headphones is little different than the practice of hiding behind a newspaper or book, which Schivelbusch (1980) proposes evolved as travellers' attempted to manage personal space in the close proximity of Victorian travel. Music and newspapers in the travel environment are one subject of our attention in later turning to our new empirical evidence.

Thus, the experience of travel particularly in relation to technologies should be understood as dynamic rather than static. Emergent technologies, or the technological applications that are reshaping existing technologies, such as the mobile phone, are potentially giving technological affordances to new ways of experiencing travel or using travel time. Recognition of this dynamic, explored through empirical evidence in this paper, strongly suggests that there should be implications for the way travel time (and travel time savings) are treated within transport planning. 
Many of the concepts above point towards the nature, meaning and significance of travel time use. It is important to offer a reminder that travel time experience varies from person to person and from trip to trip - some is positive, some is negative (Lyons and Urry, 2005). However, the UK approach to economic appraisal of transport investment - a method that has applied since the 1960s - assumes that travel during the course of the working day represents unproductive ('wasted') time which is a cost to the economy. Meanwhile travel time outside the working day is a 'cost' to the individual and individuals are willing to pay for quicker journeys. In both cases, savings in travel time amount to economic benefits. Such benefits frequently represent the majority of the total benefits deemed to accrue from a transport investment and hence determine whether the resultant benefit to cost ratio is able to justify a decision to invest. Criticism of this approach for its apparent oversight of the positive utility of travel has been longstanding. However deliberations that have ensued to address such criticism are complex and in some respects unresolved, due, to a significant extent, to the problems of measuring time use and its value. There is not space within this paper to offer a full background to these issues though this can be found across a number of existing articles (Wardman, 1998; Fowkes, 2001; Mackie et al, 2003; Lyons, 2006; Lyons et al, 2007; Fickling et al, 2008; DfT, 2011b, DfT 2009).A number of authors have also been progressing the consideration of multitasking as a (travel) time use phenomenon. Some are doing so specifically in the context of activities on the move (e.g. Waerden et al 2009). Kenyon (2010) focuses on persisting methodological challenges associated with how people's participation in more than one activity at a time is recorded while and Mokhtarian (2011) offer a conceptual framework for treatment and analysis with consideration of share of time and share of attention. 
With such insights as background we now turn to introduce the survey that has provided the data for this paper's own empirical examination of travel time use.

\section{National Passenger Survey (NPS)}

The NPS is an annual survey now administered by Passenger Focus. Each year the survey secures over 50,000 responses across two waves in an effort to gauge passenger satisfaction with rail services. Response data are weighted to be representative of the national profile of rail passengers. Details of the survey design can be found in Lyons et al (2007) and Continental Research (2005). An invitation was extended to design and include questions on travel time use in the Autumn 2004 survey wave. The authors submitted a successful proposal for inclusion of some of these questions again in the Autumn 2010 survey wave (see Figures 1 and 2). The main fieldwork for this wave took place between 2 September and 9 November 2010. Self completion questionnaires were distributed at some 700 stations across Great Britain (Passenger Focus, 2011). Passengers are asked to complete the questionnaire when they have completed their journey. Questions in the survey refer specifically to the train the individual was on following receipt of the questionnaire. 27,556 responses were obtained.

Figures 1 and 2 about here

Examination of the full response dataset revealed an unexpectedly high level of nonresponse to the second part of Q36 - asking individuals to indicate the activity that they spent most time on ( $27 \%$ non response compared to $11 \%$ in 2004$)$. This has been examined and we have concluded that the questionnaire layout was potentially the cause - the 
respondent's eye may have been drawn to the question below having looked at the first column of tick boxes, thus missing the second column for Q36. In 2004 the equivalent question was at the bottom of the page. To enable meaningful comparison between the two years we have made the following adjustments to address non-responses in both survey years: (i) survey respondents who did not indicate an activity they spent most time on and who indicated more than one activity they spent any time on have been removed from the sample; and (ii) where a respondent has only indicated one activity they spent any time on and not indicated an activity they spent most time on we have assumed the latter is the same as the former and retained the response in the final sample for analysis.

The result of this is that the 2004 sample of 26,221 has reduced to 22,866; and the 2010 sample of 27,556 has reduced to 19,715 . Examination of the effect of the steps above on distribution of responses to given questions finds that the level of non-response and our subsequent remedial steps have not biased the data. The data remain weighted by Train Operating Company (TOC), journey purpose and weekday/weekend - as applied by the NPS itself in order to be representative of national rail travel in each of the survey years. We have not been entitled to access to breakdown of data by TOC. However, the 2010 distribution of rail trips nationally by journey purpose compares closely to that for 2004 $47 \%$ of trips were for commuting in 2010 compared to $44 \%$ in $2004 ; 15 \%$ were for business in 2010 compared to $16 \%$ in 2004 and $38 \%$ were for leisure compared to $40 \%$ in 2004 . Other contextual changes on the railway over this period were an increase in passenger-kilometres of some $20 \%$, with a slight reduction in the proportion being carried by London and South East services and a slight increase in long distance and regional services. This was balanced by an increase in train kilometres of some $11 \%$ and an increase in some train capacities 
through additional carriages. Punctuality increased slightly from $80 \%$ to $85 \%$ of trains meeting performance targets.

All subsequent reporting of results and percentages are based on the resulting samples produced above. The significance of the relationships between the main variables within the following section have been statistically tested and confirmed. T-tests were used for this purpose. Differences reported are statistically significant. For further multivariate analysis of the relationships between journey experience and respondents' socio-demographic characteristics alongside their views on their time use, please see Susilo et al. (2012).

\section{Survey findings - how travel time is used}

Consistency between 2004 and 2010

Table 1 reveals notable consistency between 2004 and 2010 in terms of the relative overall proportions of people reading for leisure, window gazing/people watching, working/studying, talking to other passengers, sleeping/snoozing, being bored and eating/drinking. Such activities (with the exception of one's means of working/studying) are able to be independent of technological development so such stability over six years seems appropriate. Meanwhile, the technology-dependent activities - text messages/ phone calls and listening to music/radio/podcast - have all increased in their extent of occurrence over the six year period. We return to this shortly.

We have also drawn consistent observations between our 2004 and 2010 results in relation to: boredom; directions of travel; class of travel and journey duration. For a more developed 
account of these issues see Lyons et al (2007). In summary, we have observed the following. A small minority of people associate a rail journey with boredom. There is little difference in the overall pattern of activity engagement between outbound and return journeys - though some difference for business travellers we suggests reflects a switch in the (perceived) ownership of time from employer (outbound) to employee (return). First class travellers are much more likely than standard class travellers to spend most time working/studying. Journeys of 1-3 hours are most conducive to working/studying. For journeys of short duration, window gazing/people watching as the main activity increases in likelihood. This said, listening to music/radio/(podcast) increases as the main activity as journey duration decreases. We suggest this may relate to improvement in the portability, usability and social acceptability of music on the move.

\section{Popular activities}

Reading for leisure and window gazing/people watching together represent the activities that the majority of all passengers spend most of their time engaging in on the train. Reading for leisure is the most commonly undertaken activity overall. The majority of commuters (over $60 \%$ ) do this for part of their journey and over $40 \%$ do this as their main activity. Leisure travellers are less likely to read for leisure (around half spend some of their journey doing so) and business travellers least of all, but even here around a quarter have this as the activity they spend most time on. Window gazing/people watching as an activity undertaken some of the time has seen a modest reduction between 2004 and 2010 . 
The third most common activity engaged in concerns personal text messages/phone calls. However, this is not the case in terms of an activity that people spend most time on in their journeys ( $2 \%$ of all travellers). The third most common activity passengers spend most time on in their journeys is working/studying $-14 \%$ of all passengers. This shows almost no change over the six years from 2004. Over half of all business travellers spend some time working/studying on the train and around a third have this as the activity they spend most time on. In fact other activity response categories also (probably) reflect working/studying. Nearly $8 \%$ of business travellers indicate spending most time on either checking email (4$5 \%$ ) or work texting/phoning (3\%) - we therefore infer that the proportion of people working as their main activity may be increasing (albeit that 'checking email' was not an available response category in 2004) - a finding in line with Fickling et al (2008).

The march of the information age in six years and the growing role of sound There have been notable changes between 2004 and 2010 in the use of information and communications technologies (ICTs). Not identified as specific activity categories in 2004, internet browsing and checking emails are prevalent in 2010 with 1 in 5 commuters and nearly 1 in 3 business travellers now doing the latter ( 1 in 20 passengers overall are also accessing social networking sites). Text messaging and making phone calls is still not something that occupies many passengers as the activity they spend most time on although in terms of a time use for at least part of a train journey then such communication has grown - passengers in 2010 are 63\% more likely to be texting or phoning for personal reasons and $83 \%$ more likely to be doing so for work. It should be noted that we do not know how such technology-enabled time uses have changed in individuals' lives as a whole between 2004 and 2010 beyond the confines of the railway carriage. This could well have a 
bearing on the nature and extent of time use during train journeys themselves (Holley et al (2008) examine this notion of a wider time use context in which to then specifically consider travel time use). It is clear that technology is permeating or 'infecting' the carriage environment as people increasingly communicate external to this (though in the case of email the balance between online or offline checking while on the train is not known).

There has been a marked change in the proportions of people listening to music/radio/(podcast) - a doubling overall in six years ( 1 in 5 now do so for some of the time and for $8 \%$ it is now the activity they spend most time on - compared to $4 \%$ in 2004). This may have been facilitated by the increasingly available and portable nature of musicplaying technology, perhaps allied to the growth of music downloads and the ease of assembling mobile personal music collections. It may also reflect a change in social acceptability of this practice and better earphone technology reducing or eliminating annoyance for other passengers. As discussed earlier, such an activity has the potential to act as an aid in 'personalising public space' from an acoustic point of view (and potentially discouraging interaction with other passengers). We cannot be sure from the two surveys to what extent such acoustic purpose is applying in practice and how this is changing. In relation to discouraged interaction with other passengers all we can observe is that talking to other passengers has decreased a little over six years. It is important to acknowledge that the appeal of listening to music (or reading a newspaper) is unlikely to be confined to a purpose of personalising public space. People in some instances may welcome the proximity of other passengers as an accompaniment to the relaxation they achieve from such time uses. 


\section{Gender and travel time use}

There are marginal differences in how men and women use their travel time, which may be linked to employment structures, as well as social trends in technology ownership and use. Men are more likely than women to spend some of their travel time: working/studying (32\% versus $24 \%$ ); texting/phoning for work ( $18 \%$ versus $12 \%$ ); checking emails ( $21 \%$ versus $14 \%$ ); internet browsing (12\% versus $8 \%$ ); and playing games (5\% versus $3 \%$ ). Meanwhile women are more likely than men to spend some of their travel time: talking to other passengers (15\% versus $12 \%)$; and personal texting/phoning (35\% versus $25 \%$ ). Such gender distinctions apply for commuting and, broadly but less so, for leisure travel. There is also some consistency between commuters and business travel however here there is greater similarity between genders in terms of the likelihood of working/studying when travelling for business.

\section{Survey findings - how worthwhile is rail travel time use?}

Table 2 shows how passengers judge the degree to which their travel time is worthwhile. While the survey question specifically focuses attention here on a respondent's experience of his or her time on the train it must be noted that the respondent's interpretation of what is meant by 'worthwhile' is subjective. The survey did not allow us to learn why such time was or was not worthwhile. Existing literature (summarised earlier) offers some insights but this remains an important consideration for future qualitative research. Overall the proportion of people considering their time wasted has gone down by nearly a third in six years from $19 \%$ to $13 \%$ of all passengers. Correspondingly the proportion of people making very worthwhile use of their time has gone up by a quarter - from $24 \%$ to $30 \%$. In terms of proportional changes over the six years, leisure travellers have seen the greatest change in 
terms of making very worthwhile use of their time $-36 \%$ more leisure travellers indicating this in 2010 compared to 2004 . There has been a $37 \%$ reduction over six years in the proportion of business travellers indicating that their time on the train was wasted.

Table 2 about here

There is a strong overall message here that worthwhile use of rail travel time has increased over the six year period. This may in part reflect how rail service provision is perceived to have changed over this time. Corresponding to (though with no evidence it is necessarily related to) the increase in travellers who considered their time use had been very worthwhile, the proportion of travellers who were very/fairly satisfied with the punctuality/reliability of their train has grown by $15 \%$ (from $71 \%$ to $82 \%$ ) and the proportion of travellers who rated the train very good or good in terms of there being sufficient room for all the passengers to sit/stand has also grown by $15 \%$ (from $59 \%$ to $68 \%$ ). Overall improvement in service provision is accompanied by an improvement in worthwhile time use. The greater proportional increase in worthwhile time use we suggest may relate to improvement in terms of how individuals are equipping themselves for travel (see later).

Table 3 considers how passengers rate their time use according to their journey purpose and the activity upon which most time was spent. For example, in the top row of the Table it shows that $31 \%$ of those commuters who spent most of their time reading for leisure considered their time on the train to be very worthwhile. Rail travellers are most likely to indicate finding their time use very worthwhile when they spend the most time on their train journeys working/studying. $46 \%$ who spent most time on this activity found their time 
use very worthwhile. Corresponding figures for other 'worthwhile' activities are as follows: text messages/phone calls (work) - 42\%; checking emails - 39\%; eating/drinking - 38\%; and reading for leisure $-34 \%$.

Table 3 about here

In terms of the thing people spend most time doing, three activities account for $71 \%$ of all journeys - reading for leisure, window gazing/people watching and working/studying. For all three of these there are substantial increases in six years in the proportion who consider their time spent to have been very worthwhile. Few passengers who spend most time reading for leisure or working/studying consider their time to have been wasted. Across the three activities, leisure travellers are most likely to consider their time use very worthwhile - twice as likely as commuters for window gazing/people watching and even higher than business travellers for working or studying. This highlights the significance of context for how travel time use is experienced and judged. Indeed we suggest this may reflect the relaxed state of mind surrounding a journey for leisure.

Three activities (window gazing/people watching, listening to music/radio/podcast and sleeping/snoozing) produce polarised views from travellers overall with around a fifth seeing their time as very worthwhile and another fifth seeing their time as wasted. This is a reminder that the same activity can have different appeal to different individuals and indeed the same individual for different journeys. Simply knowing what people are doing is not enough. We refer back to our earlier reference to the work of Watts (2008) and Bissell (2008) and their notions of the crafting of travel time and the different states of mind and 
sense of the passage of time that can become manifest as people embed themselves within the travelling environment.

Notwithstanding the small proportions of first class travellers, in 2010 as in 2004, a greater proportion of first class travellers considered they had made very worthwhile use of their time compared to standard class travellers - $44 \%$ compared to $30 \%$ ( $33 \%$ compared to $24 \%$ in 2004). In 2004, the proportion of people who considered they had made very worthwhile use of their time increased through the age bands. This was similar in 2010 but with more consistency for those aged 35 and above. $18 \%$ of $16-25$ year olds considered their time use to have been very worthwhile in 2010 compared to $25 \%$ of $26-34$ year olds and $31 \%$ of 35 44 year olds.

\section{Survey findings - the support of travel time use}

\section{Advance planning}

Table 4 shows the extent of planning in advance for how to use the time on the train. An important revision to the response options was made in 2010 with the inclusion of 'very little as I always use my journey time the same way'. The revision was made following reflection on the qualitative research conducted in 2004-5 that sought to explore the context of travel time use. This revision has clearly proved significant. It underlines that for the majority of commuters (72\%) very little or no advance planning of time use takes place largely on the basis that this is a regular/routine part of their lives for which established practices exist. 
Table 5 goes on to highlight how advance planning relates to the assessment of travel time worth. Individuals who have planned a lot in advance are three times more likely to consider their time use very worthwhile compared to those who have not planned at all, and seven times less likely to consider their time has been wasted. Comparable observations applied for 2004 - planning in advance improves the prospects of getting more out of one's journey.

We have earlier suggested (drawing on Stradling (2006)) that those in very familiar travelling situations (notably commuters) would tend to have lower cognitive and affective effort associated with the journey itself, leaving more opportunity to benefit from the travel time use experience. Yet our results show that while nearly half of commuters indicated that they have established practices of travel time use, only $27 \%$ of commuters indicated that they had made very worthwhile use of their time.

We suggest that (other) factors at work here could include established practices being 'OK' for passing time or even appreciated as welcome 'down time' or 'me time' but not being judged as very worthwhile. It might also be that formed habits and satisficing behaviour obstruct the reviewing of and revising established practices in a way that could get more out of the time on the train. Journeys may be worthwhile in parts, e.g. the first half where work is completed, but may be less worthwhile later. Work by Watts and Lyons (2010) has highlighted how the variability across a routine travel experience can be 'remedied' by reviewing and revising how a traveller is equipped and his or her state of mind in approaching the journey. For example, recognising that the last third of a 90 minute journey may become boring as tasks are completed gives rise to thinking how can this time 
be best equipped for relaxing or refreshing personal energy levels. As Bissell (2008) describes, comfort does not come automatically, the body and mind have to continuously seek comfort while travelling.

Table 5 about here

We suggest that the overall amount of rail travel in an individual's daily life could also affect how 'worthwhile' time on any given train journey is considered to be. The train environment may be well suited to certain time uses but if there is more rail travel time in a person's life than he or she needs or desires for such uses then the appeal of rail travel time may diminish. For example, one may relish being able to read on the train once or twice a week, but if one has a daily two-hour train commute then 10 hours reading a week may be more than is wanted. Meanwhile, individuals who plan a lot in advance may be seeking to make the most of a less frequent opportunity for some time out and accordingly get more out of that time when on the train.

\section{Equipped travel and the newspaper puzzle}

Table 6 compares the extent to which items were both to hand and used between 2004 and 2010. The following items show little difference over 6 years: reading book; text book; magazine; and paperwork. $54 \%$ of people overall read for leisure during a train journey the figures in Table 6 reflect that this reading may relate to a number of different carried media.

Table 6 about here 
There appear to be changing fortunes for the newspaper - in 2004 the majority (79\%) had a newspaper to hand - by 2010 this had reduced to a minority (45\%). Meanwhile the proportion of passengers using a newspaper during their train journey has changed very little (in other words those who have a newspaper with them are more likely now to be those inclined to use it). This may be a reflection in part of the fact that the newspaper industry has been facing decline for a number of years - just over $21 \%$ between 2007 and 2009 (OECD, 2010)). We would suggest that this change could also highlight that for many people having a newspaper to hand was to enable the creation of psychological distance from other passengers - something now increasingly able to be achieved through other artefacts and in particular personal music-playing devices. One might also note the trend towards free daily newspapers targeted at public transport travellers.

\section{Keeping pace with technological advance}

Taking netbooks and laptops together then the proportion of people with such a device has increased by $77 \%$ in six years from $7 \%$ in 2004 to $13 \%$ in 2010 . The proportion of travellers who have and use a laptop computer has increased by $60 \%$. The proportion of people with a mobile phone has only increased modestly over the six years. However, a much higher proportion of those who have a phone with them are now using it during the journey - $54 \%$ compared to $36 \%$ for 2004 . The proportion of people who have a music player, and the proportion who have one and use it, have doubled in six years. The extent of being equipped for sound may be even greater given the capacity of modern mobile/smart phones to store and play music. However, having a device capable of music playing does not mean the owner knows it has this capacity, or has loaded it up with music. In such instances for practical purposes it might be said that they are not equipped for sound. 
It is increasingly difficult to know what functionality a device has. Thus 'mobile phone' in its earliest guise made phone calls and then text messages. Now the latest (smart) phones have touch screens and can be used to browse the internet, take and view photos, check and send emails, store and play music and listen to podcasts and play games.

\section{Concluding discussion}

The passenger experience and the phenomenon of multitasking on the move have captured academic interest in the social sciences and transport studies and the body of literature has continued to develop since the time of the 2004 survey. In both territories there is a deepening appreciation and understanding while at the same time it becomes just as apparent that there is much more to learn about the human condition in this context. Passengers actively engage in making themselves comfortable - physically and psychologically (Bissell, 2008) and may achieve this through the (in)activity they undertake. For instance, daydreaming and looking out of the window may not be economically beneficial, but it may contribute positively to an individual's emotional response to the commute. Ettema et al (2012) indicate that talking to other passengers and listening to music are beneficial to cognitive evaluation, suggesting that these activities may reduce boredom or stress. The latter is supported by Skånland's research on MP3 use (2011). Yet on the bus, Clayton (2012) argues that doing more activities using mobile technologies does not impact on levels of boredom. Different opportunities to engage with an activity or relax (whether technologically enabled or not) link with individuals' expectations or desires for the journey time experience (Holley et al, 2008). 
The particular contribution of this paper to the growing body of insights into travel time use comes from the unique opportunity for a longitudinal assessment of rail travel time use enabling indications of both stability and change over time to be highlighted,

We find that there is broad consistency over time in terms of the most popular activities reading for leisure, window gazing/people watching and working/studying endure. The two key findings of change from this temporal comparison are the increased proportion of passengers considering their travel time use very worthwhile (and thereby a decreased proportion considering their time wasted) and the increased use of mobile communications technologies. It seems likely that the two are linked and it is indicative of the literature around comfort and travel time use that where the individual has control to manage and manipulate time use then there is a positive outcome. This perhaps supports the notion that 'being' a passenger is distributed through the heterogeneous carried items with the physical context of the travel space (Watts, 2008, Bissell, 2008).Questions we were not able to repeat in 2010 because of space but asked in 2004 concerned whether passengers felt that the electronic devices they had with them had made their time better or seem to pass more quickly. Over a fifth to whom the question of 'better' applied indicated that the time had been made a lot better; meanwhile $46 \%$ indicated no effect. $46 \%$ indicated the time seemed to pass quicker by having electronic devices ( $32 \%$ indicated 'no' to this). We suspect there would have been a strengthening of the view of 'better' and 'quicker' in relation to travel time six years on. This relates to Watts' (2008) notion of experienced time being able to be stretched or compressed. 
The substantial increase in listening to music/radio/(podcast) signals strong prospects that people are increasingly able to create psychological distance from other passengers and a private space for (better) engaging in other activities. At the same time, other technologies and their use are permeating and infecting this private space as people communicate with others remote from the train via email, texting, phoning and social networking. We see an important ongoing need in research terms to monitor change over time in this regard - are mobile technologies ultimately on a trajectory of positively enriching the experience of travel time or are they conversely set to undermine some of the characteristics of the 'interspace' of travel by reconnecting it with the world beyond?

While some passengers actively seek ways of making their travel time worthwhile it is apparent that activities on the move can become habituated. It has been revealing that passengers who indicate they plan very little because they always use the travel time in the same way are not emerging correspondingly as those most likely to consider their time use very worthwhile. We suggest there is an important challenge / opportunity for both employers and rail operators to address here through approaches that aim to influence traveller behaviour such that they can increase the worthwhile nature of rail travel time use(as Watts and Lyons (2010) have demonstrated is possible through their travel remedy kit). It is a reminder that positively experienced travel time and time use is not a given but may be something that has to be consciously worked at or crafted (Bissell, 2008; Watts, 2008).

Our empirical evidence has been limited by the questions we were able to ask. We do not have specific data on the duration of different activities within people's journeys or any 
robust metrics of (relative) productivity for travel time use. This limits the extent to which we are able to challenge the way travel time (savings) are valued in economic appraisal of transport investment. However, it is telling to note that the UK Department for Transport is having to explicitly address doubts in its approach to provide assurances that its economic case for high speed rail is sound. One of the frequently asked questions set out on the Government website (http://www.dft.gov.uk/pgr/rail/pi/highspeedrail/faq) is as follows: "I've heard that the business case is based on the idea that all the time passengers spend on train is wasted. Isn't that stupid?". This is correspondingly addressed at some length in the economic appraisal report for high speed rail (DfT, 2011a). While our study cannot offer revised 'values of time' as alternatives for the process of economic appraisal in light of how people use their time on trains, we do believe our findings raise other important issues to be acknowledged and perhaps accounted for. Travel time use and how worthwhile it is considered to be (reflective of its 'value') are changing over time in the face of the information age and its transformation of how people communicate, conduct business and leisure activity. Our research also reveals that it is very difficult to attribute ownership of time - something else significant to economic appraisal which distinguishes between an individual's own time and that paid for by his or her employer (in the case of business travel). There is evidence of people seemingly doing their employer's bidding in their own time (notably working during the commute) and using their employer's time for their own (for instance reading for leisure during business travel). The information age is creating greater flexibilities in where and when we undertake certain activities.

We conclude by underlining that while rail travel may see its prospects improve through the provision of higher levels of service and capacity provision on the part of government and 
transport providers, we should not underestimate the prospects of improvement through the increasing capacity and opportunity for mobile technology and service providers to equip people on the move and support their time use. That said, and as we have noted above, individuals can have to work to craft their travel time experience. While we have observed a positive trend over time in the apparent success of this, prospects remain for mobile technologies to also erode some of the inherent appeal of travel time as a source of detachment from the awaiting forms of engagement and performance at either ends of the journey.

We would be confident that travel time use and its meaning will continue to be the subject of a broad constituency of research interest. Key priorities we see are as follows: (i) the ability to apply suitable mixed-method approaches that are able to capture both what people are doing with their time as well as why they are doing it and with what significance to them and others; (ii) the means to be able to draw comparative insights across the growing body of literature as to how travel time use plays out in different geographic and cultural settings; and (iii) the need to continue to understand whether and how over time the making of travel time and its social and economic value is changing.

\section{Acknowledgements}

We are very grateful to Passenger Focus for the opportunity to include questions on travel time use in the NPS and extend their thanks in particular to David Greeno and lan Wright for their support. The University of the West of England, Bristol (UWE) is acknowledged for providing the time resources to enable this research to be pursued. We finally extend our 
thanks to the four anonymous reviewers of the initial version of this paper for the constructive feedback which has helped develop and shape this final version. 


\section{References}

Bissell, D. (2008). Comfortable bodies: sedentary affects. Environment and Planning A, 40, 1697- 1712.

Brown, B., O'Hara, K., 2003. Place as a practical concern of mobile workers. Environment and Planning A, 35, 1565-1588.

Bull, M. (2000). Sounding out the city. Personal Stereos and the management of everyday life. Oxford: Berg.

Circella, G., Mokhtarian, P. And Poff, L. K. (2011). A Conceptual Typology of Multitasking Behavior and Polychronicity Preferences, presented at the $90^{\text {th }}$ Annual Meeting of the Transportation Research Board, Washington, DC, January.

Continental Research (2005). National Passenger Survey overview document: Autumn 2004 (wave 11). Prepared for the Strategic Rail Authority, January.

DfT (2009). Value of Working Time and Travel Time Savings. Long run implications report, Department for Transport, December, London.

DfT (2011a). Economic case for HS2: The Y network and London - West Midlands. Department for Transport, February, London.

DfT (2011b). Values of Time and Operating Costs. Transport Analysis Guidance (TAG) Unit 3.5.6, Department for Transport, April, London.

Du Gay, P., Hall, S., Janes, L., Mackay, H., and Negus, K. (1997). Doing Cultural Studies: the Story of the Sony Walkman. Sage, London.

Ettema, D., Friman, M., Gärling, T., Olsson, L. and Fujii,S. (2012, in press). How in-vehicle activities affect work commuters' satisfaction with public transport. Journal of Transport Geography. 
Fickling, R., Gunn, H., Kirby, H., Bradley, M. and Heywood, C. (2008). The productive use of rail travel time and value of travel time saving for travellers in the course of work. Proc. European Transport Conference, Leeuwenhorst Conference Centre, The Netherlands.

Fowkes, A. S. (2001). Principles of Valuing Business Travel Time Savings. ITS WP 562, Institute for Transport Studies, University of Leeds.

Gripsrud, M., and Hjorthol, R. (2009). Working on the train: from "dead time" to contractual time. Fourth Specialist Meeting of the Network 'ICTs: mobilizing persons, places and spaces', Québec, Canada, 7-9 October.

Hensher, D.A. (1977). Value of Business Travel Time. Pergamon Press, Oxford.

Holley, D., Jain, J. and Lyons, G. (2008). Understanding Business Travel Time Use and its Place in the Working Day. Time \& Society, 17 (1), 27-46.

Jain, J. (2006). Bypassing and WAPing: Reconfiguring Timetables for Real Time Mobility. In: Sheller M and Urry J (eds) Mobile Technologies of the City. Routledge, London.

Jain, J. and Lyons, G. (2008). The gift of travel time. Journal of Transport Geography, 16, 8189.

Kenyon, S.L. (2010). What do we mean by multitasking? - Exploring the need for methodological clarification in time use research. Electronic International Journal of Time Use Research, 7(1), 42-60.

Kenyon, S. and Lyons, G. (2007). Introducing multitasking to the study of travel and ICT: examining its extent and assessing its potential importance. Transportation Research, 41(A), 161-175. 
Kirby, H.R., Smyth, A.W. and Carreno, M. (2006). Exploring the relative costs of travelling by train and by car. Final Report to Virgin Trains. TRi Record 01/12/06, Transport Research Institute, Napier University, Edinburgh.

Laurier, E. (2002). The Region as a Socio-technical Accomplishment of Mobile Workers. In Brown, B, Green, N, and Harper, R, (eds) Wireless world: social and interactional aspect of the mobile age. Springer-Verlag, London

Lyons, G. (2006). Travel Time Use - Developing a Research Agenda. Department for Transport, London.

Lyons, G., Jain, J. and Holley, D. (2007). The use of travel time by rail passengers in Great Britain. Transportation Research, 41(A), 107-120.

Lyons, G. and Chatterjee, K. (2008). A human perspective on the daily commute: costs, benefits and trade-offs. Transport Reviews, 28(2), 181-198.

Lyons, G. and Urry, J. (2005). Travel time use in the information age. Transportation Research, 39(A), 257-276.

Lyons, G., Jain, J. and Holley, D. (2007). The use of travel time by rail passengers in Great Britain. Transportation Research, 41(A), 107-120.

Mackie, P.J., Fowkes, A.S., Wardman, M., Whelan, G., Nellthorp, J. and Bates, J. (2003). Value of Travel Time Savings in the UK. Department for Transport, July, London.

Mokhtarian, P.L., Salomon, I. (2001). How derived is the demand for travel? Some conceptual and measurement considerations. Transportation Research, 35(A), 695719.

OECD (2010). The evolution of news and the internet. DSTI/ICCP/IE(2009)14/FINAL, Directorate for Science, Technology and Industry, Organisation for Economic Cooperation and Development. 
Ohmori, N. and Harata, N. (2009). How different are activities while commuting by train? A case in Tokyo. Tijdschrift voor Economische en Sociale Geografie, 34(1), 547-561.

Passenger Focus (2011). National Passenger Survey: Autumn 2010 main report. Passenger Focus, London.

Russell, M., Price, R., Signal, L., Stanley, J., Gerring, Z. and Cumming, J. (2011). What Do Passengers Do During Travel Time? Structured Observations on Buses and Trains. Journal of Public Transportation, 14(3), 123-146.

Schivelbusch, W. (1980). The Railway Journey. Trains and Travel in the 19th Century. Blackwell, Oxford.

Simun, M. (2009). My music, my world: using the MP3 player to shape experience in London. New Media \& Society, 11(6), 921-941.

Skånland, M. (2011). Use of MP3 Players as a Coping Resource. Music and Arts in Action, 3 (2), 15-32.

Stradling, S. (2006). The Psychology of Travel. Review for the Foresight 'Intelligent Infrastructure Systems' Project, Office of Science and Technology, Department for Trade and Industry, London.

Susilo, Y., Lyons, G., Jain, J. and Atkins, S. (2012). Rail Passengers' Time Use and Utility Assessment: 2010 findings from Great Britain with multivariate analysis. Proc. 91st Annual Meeting of the Transportation Research Board, Washington, D.C., January; and forthcoming in Transportation Research Record.

Transport Committee (2011). High Speed Rail. Tenth Report of Session 2010-12 Volume 1 Report and formal minutes, House of Commons Transport Committee, The Stationery Office Limited, London, November. 
Transport Committee (2011). High Speed Rail. Tenth Report of Session 2010-12 Volume II Oral and written evidence, House of Commons Transport Committee, The Stationery Office Limited, London, November.

Transport Committee (2011). High Speed Rail. Tenth Report of Session 2010-12 Volume III Additional written evidence, House of Commons Transport Committee, The Stationery Office Limited, London, October.

Waerden, P.J.H.J. van der, Timmermans, H.J.P. and Neerven, R. van (2009). Extent, Nature and Covariates of Multitasking of Rail Passengers in an Urban Corridor: A Dutch Case Study. Transportation Research Record, 2110, 106-111.

Wardman, M. (1998). The Value of Travel Time - A Review of British Evidence. Journal of Transport Economics and Policy. 32 (3), 285-316.

Watts, L. (2008). The Art and Craft of Train Travel. Journal of Social and Cultural Geography, 9(6), 711-726.

Watts, L. and Lyons, G. (2010). Travel Remedy Kit: Interventions into Train Lines and Passenger Times, in Buscher, M. Urry, J. and Witchger, K. (eds.) Mobile Methods, London, Routledge. 


\section{Section 4: Travel time use}

\section{All answer}

Q36 How did you spend your time on the train you got on at Watford Junction station?

Tick all

that apply

Tick one spent

Sleeping/snoozing

.... $\square$

Reading for leisure.

Working/studying (reading/writing/thinking).

Talking to other passengers.

Window gazing/people watching.

Listening to music/radid Podcast.

Watching a film/video

Text messages/ phone calls - work.

Text messages/ phone calls - personal.

Checking emails..

Internet browsing

Accessing social networking sites

Eating/drinking.

Caring for someone travelling with you (including children)

Playing games (electronic or otherwise)

Being bored.

Being anxious about the journey (e.g. delays or where to get off)

Planning onward or return journey.

Other: Please write in

Q37 Thinking about the time you spent on the train from Watford Junction, which one of the following statements do you most agree with?

I made very worthwhile use of my time on this train today.

I made some use of my time on this train today.

My time spent on this train today is wasted time....

Figure 1. NPS travel time use questions - 36 and 37 (with modification since 2004 highlighted)

Q38 Which of the following did you have at hand on the train from Watford Junction, and which did you use?

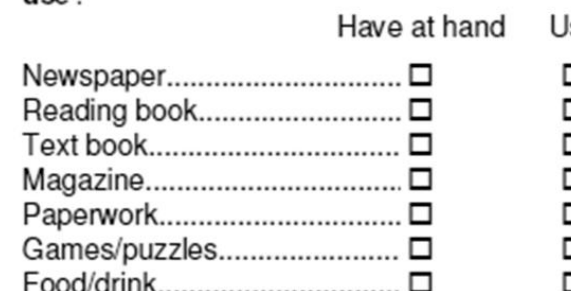

Use
$\square$
$\square$
$\square$
$\square$
$\square$
$\square$
$\square$

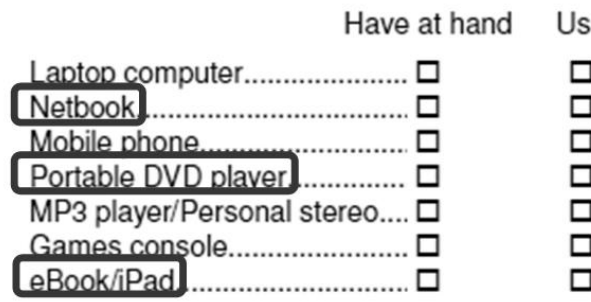

Q39 To what extent had you planned in advance how you would spend the time on this train?

A lot.

A little

Very little as I always use my journey time the same way

Not at all.....

Figure 2. NPS travel time use questions - 38 and 39 (with modification since 2004 highlighted) 
Table 1. Comparison for 2010, by journey purpose and direction of travel, of the percent of travellers undertaking activities for some time during the train journey and (shown in brackets) for most of the time; shaded rows show 2004 results - only activities undertaken by at least $10 \%$ of respondents are shown

\begin{tabular}{|c|c|c|c|c|c|c|c|c|}
\hline \multirow{3}{*}{ activity } & \multicolumn{8}{|c|}{ journey purpose } \\
\hline & \multicolumn{2}{|c|}{ all } & \multicolumn{2}{|c|}{ commute } & \multicolumn{2}{|c|}{ business } & \multicolumn{2}{|c|}{ leisure } \\
\hline & out & return & out & return & out & return & out & return \\
\hline \multirow[t]{2}{*}{ Reading for leisure } & $54(38)$ & $56(38)$ & $63(46)$ & $62(44)$ & $42(23)$ & $46(28)$ & $47(34)$ & $50(34)$ \\
\hline & $53(37)$ & $57(39)$ & $62(47)$ & $64(46)$ & $43(25)$ & $53(32)$ & $46(31)$ & $51(35)$ \\
\hline \multirow[t]{2}{*}{ Window gazing/people watching } & $53(20)$ & $54(19)$ & $45(12)$ & $48(12)$ & $43(11)$ & $50(15)$ & $65(32)$ & $63(31)$ \\
\hline & $56(20)$ & $58(20)$ & $50(13)$ & $48(13)$ & $51(13)$ & $59(15)$ & $67(31)$ & $69(30)$ \\
\hline \multirow[t]{2}{*}{ Text messages/phone calls - personal } & $29(2)$ & $32(2)$ & $32(2)$ & $37(3)$ & $23(2)$ & $31(1)$ & $28(2)$ & $25(2)$ \\
\hline & $17(1)$ & $22(1)$ & $18(1)$ & $25(1)$ & $13(1)$ & $17(1)$ & $17(1)$ & $20(2)$ \\
\hline \multirow[t]{2}{*}{ Working/studying } & $27(14)$ & $27(14)$ & $31(13)$ & $31(14)$ & $57(38)$ & $52(31)$ & $12(6)$ & $11(4)$ \\
\hline & $26(15)$ & $26(14)$ & $27(14)$ & $29(15)$ & $55(39)$ & $49(30)$ & $14(7)$ & $13(6)$ \\
\hline \multirow[t]{2}{*}{ Listening to music/radio/podcast * } & $20(8)$ & $21(8)$ & $28(10)$ & $28(10)$ & $14(5)$ & $15(5)$ & $13(5)$ & $14(6)$ \\
\hline & $9(4)$ & $9(4)$ & $12(5)$ & $13(5)$ & $4(1)$ & $5(1)$ & $7(3)$ & $7(3)$ \\
\hline Checking emails \# & $17(2)$ & $17(2)$ & $21(3)$ & $20(2)$ & $31(4)$ & $33(5)$ & $7(1)$ & $6(1)$ \\
\hline \multirow{2}{*}{ Eating/drinking } & $17(1)$ & $17(1)$ & $12(0)$ & $14(0)$ & $22(1)$ & $24(1)$ & $20(1)$ & $20(1)$ \\
\hline & $13(0)$ & $18(1)$ & $8(0)$ & $11(0)$ & $19(0)$ & $26(1)$ & $18(0)$ & $22(0)$ \\
\hline \multirow[t]{2}{*}{ Text messages/phone calls - work } & $15(1)$ & $15(1)$ & $18(2)$ & $16(1)$ & $31(3)$ & $35(3)$ & $6(0)$ & $4(0)$ \\
\hline & $8(1)$ & $8(1)$ & $7(1)$ & $9(1)$ & $22(2)$ & $20(2)$ & $3(0)$ & $3(0)$ \\
\hline \multirow[t]{2}{*}{ Talking to other passengers } & $14(6)$ & $13(5)$ & $11(3)$ & $10(3)$ & $11(6)$ & $10(4)$ & $19(9)$ & $20(9)$ \\
\hline & $16(7)$ & $14(6)$ & $11(5)$ & $10(4)$ & $14(6)$ & $11(5)$ & $22(10)$ & $21(9)$ \\
\hline \multirow[t]{2}{*}{ Sleeping/snoozing } & $13(3)$ & $16(4)$ & $17(4)$ & $19(4)$ & $13(3)$ & $14(3)$ & $8(1)$ & $13(4)$ \\
\hline & $13(3)$ & $19(4)$ & $16(5)$ & $24(5)$ & $11(3)$ & $17(4)$ & $9(2)$ & $15(3)$ \\
\hline \multirow[t]{2}{*}{ Being bored } & $10(2)$ & $11(2)$ & $13(2)$ & $14(2)$ & $7(1)$ & $9(2)$ & $8(1)$ & $9(2)$ \\
\hline & $11(2)$ & $14(2)$ & $13(3)$ & $17(3)$ & $7(1)$ & $11(2)$ & $10(2)$ & $12(2)$ \\
\hline Internet browsing \# & $10(1)$ & $10(1)$ & $13(1)$ & $13(1)$ & $11(0)$ & $12(1)$ & $6(1)$ & $5(0)$ \\
\hline
\end{tabular}


Table 2. "Thinking about the time you spent on the train from XXX station, which one of the following statements do you most agree with?" (percent of respondents selecting each statement in 2010; equivalent figure for 2004 shown in brackets)

\begin{tabular}{lrrrr}
\hline statement most agreed with & all & commute & business & leisure \\
\hline I made very worthwhile use of my time on this train today & $30(24)$ & $27(23)$ & $34(28)$ & $32(23)$ \\
I made some use of my time on this train today & $55(55)$ & $55(53)$ & $57(58)$ & $53(55)$ \\
my time spent on this train today is 'wasted time' & $13(19)$ & $16(23)$ & $8(13)$ & $12(17)$ \\
not answered & $2(3)$ & $2(2)$ & $1(2)$ & $3(5)$ \\
\hline
\end{tabular}


Table 3. Distribution of time worth assessment (per cent of those respondents who are within the given journey purpose and who spent the most time on the activity in question) - 2004 figures shown in brackets

\begin{tabular}{|c|c|c|c|c|c|}
\hline \multirow[t]{2}{*}{ activity } & \multirow[t]{2}{*}{ time on train was: } & \multicolumn{4}{|c|}{ journey purpose } \\
\hline & & all & commute & business & leisure \\
\hline \multirow{4}{*}{ reading for leisure } & very worthwhile & $34(26)$ & $31(25)$ & $31(23)$ & $40(28)$ \\
\hline & of some use & $58(59)$ & $58(58)$ & $63(63)$ & $55(60)$ \\
\hline & wasted time & $7(13)$ & $10(16)$ & $5(12)$ & $3(8)$ \\
\hline & not answered & $1(2)$ & $1(2)$ & $0(2)$ & $2(4)$ \\
\hline \multirow{4}{*}{$\begin{array}{l}\text { window gazing/ } \\
\text { people watching }\end{array}$} & very worthwhile & $20(14)$ & $13(10)$ & $16(12)$ & $25(17)$ \\
\hline & of some use & $53(51)$ & $52(45)$ & $63(58)$ & $51(52)$ \\
\hline & wasted time & $22(30)$ & $31(42)$ & $19(28)$ & $19(25)$ \\
\hline & not answered & $5(5)$ & $5(3)$ & $2(2)$ & $5(6)$ \\
\hline \multirow{4}{*}{ working/studying } & very worthwhile & $46(40)$ & $44(37)$ & $46(42)$ & $51(40)$ \\
\hline & of some use & $51(56)$ & $52(58)$ & $52(54)$ & $45(54)$ \\
\hline & wasted time & $3(4)$ & $4(4)$ & $1(3)$ & $3(3)$ \\
\hline & not answered & $1(1)$ & $1(1)$ & $1(1)$ & $1(2)$ \\
\hline \multirow{4}{*}{$\begin{array}{r}\text { listening to } \\
\text { music/radio/podcast }\end{array}$} & very worthwhile & $17(16)$ & $17(16)$ & $14(14)$ & $17(18)$ \\
\hline & of some use & $62(52)$ & $60(52)$ & $65(53)$ & $64(54)$ \\
\hline & wasted time & $21(30)$ & $22(32)$ & $20(27)$ & $18(27)$ \\
\hline & not answered & $1(2)$ & $1(1)$ & $1(7)$ & $1(2)$ \\
\hline \multirow{4}{*}{$\begin{array}{l}\text { talking to other } \\
\text { passengers }\end{array}$} & very worthwhile & $31(25)$ & $25(20)$ & $40(24)$ & $32(27)$ \\
\hline & of some use & $50(54)$ & $54(54)$ & $45(56)$ & $50(53)$ \\
\hline & wasted time & 14 (19) & $19(25)$ & 9 (19) & $14(16)$ \\
\hline & not answered & $4(3)$ & $3(1)$ & $5(1)$ & $4(4)$ \\
\hline \multirow{4}{*}{ sleeping/snoozing } & very worthwhile & $21(17)$ & $20(16)$ & $21(15)$ & $25(23)$ \\
\hline & of some use & $52(45)$ & $51(43)$ & $57(57)$ & $53(45)$ \\
\hline & wasted time & $25(35)$ & $29(39)$ & $22(27)$ & $20(28)$ \\
\hline & not answered & $1(2)$ & $1(2)$ & $0(1)$ & $1(4)$ \\
\hline \multirow{4}{*}{$\begin{array}{r}\text { text messages/phone calls } \\
- \text { personal }\end{array}$} & very worthwhile & $24(23)$ & $15(25)$ & $30(26)$ & 36 (19) \\
\hline & of some use & $58(53)$ & $65(54)$ & $46(50)$ & $51(54)$ \\
\hline & wasted time & $16(20)$ & $18(21)$ & $16(12)$ & $12(22)$ \\
\hline & not answered & $3(4)$ & $2(0)$ & $9(12)$ & $2(5)$ \\
\hline
\end{tabular}


Table 3. Distribution of time worth assessment (per cent of respondents, for each (continued)activity that most time was spent on, within a given category of journey purpose) - 2004 figures shown in brackets

\begin{tabular}{|c|c|c|c|c|c|}
\hline \multirow[t]{2}{*}{ activity } & \multirow[t]{2}{*}{ time on train was: } & \multicolumn{4}{|c|}{ journey purpose } \\
\hline & & all & commute & business & leisure \\
\hline \multirow{4}{*}{ checking emails } & very worthwhile & 39 & 39 & 37 & 40 \\
\hline & of some use & 55 & 51 & 61 & 59 \\
\hline & wasted time & 6 & 9 & 2 & 1 \\
\hline & not answered & 1 & 1 & 0 & 0 \\
\hline \multirow{4}{*}{ being bored } & very worthwhile & $8(4)$ & $8(5)$ & $14(0)$ & $5(3)$ \\
\hline & of some use & $28(33)$ & $26(29)$ & $41(42)$ & $25(37)$ \\
\hline & wasted time & $62(62)$ & $62(65)$ & $45(51)$ & 67 (59) \\
\hline & not answered & 32() & $4(1)$ & $0(7)$ & $3(1)$ \\
\hline \multirow{4}{*}{$\begin{array}{r}\text { text messages/phone calls } \\
- \text { work }\end{array}$} & very worthwhile & $42(33)$ & $46(32)$ & $41(39)$ & $27(12)$ \\
\hline & of some use & $52(63)$ & $48(64)$ & $53(59)$ & $66(83)$ \\
\hline & wasted time & $5(3)$ & $7(5)$ & $1(2)$ & $7(2)$ \\
\hline & not answered & $2(0)$ & $0(0)$ & $5(0)$ & $1(2)$ \\
\hline \multirow{4}{*}{ Internet browsing } & very worthwhile & 16 & 12 & 42 & 17 \\
\hline & of some use & 68 & 68 & 56 & 76 \\
\hline & wasted time & 15 & 21 & 3 & 8 \\
\hline & not answered & 0 & 0 & 0 & 0 \\
\hline \multirow{4}{*}{ eating/drinking } & very worthwhile & $38(20)$ & $30(25)$ & $45(19)$ & 38 (19) \\
\hline & of some use & $56(75)$ & $59(67)$ & $45(80)$ & $60(75)$ \\
\hline & wasted time & $5(4)$ & $11(8)$ & $10(1)$ & $1(4)$ \\
\hline & not answered & $1(1)$ & $0(0)$ & $0(0)$ & $1(2)$ \\
\hline
\end{tabular}


Table 4. "To what extent had you planned in advance how you would spend the time on this train?" (percent of respondents equivalent

figure for 2004 shown in brackets)

\begin{tabular}{lrrrr}
\hline Planning in advance & all & commute & business & leisure \\
\hline A lot & $8(11)$ & $8(11)$ & $14(19)$ & $6(7)$ \\
A little & $23(36)$ & $19(36)$ & $35(45)$ & $23(32)$ \\
Very little as I always use my journey time the same way* & 38 & 49 & 25 & 29 \\
Not at all & $30(42)$ & $23(45)$ & $26(30)$ & $40(42)$ \\
Not stated / not applicable (2004 response options) & $1(12)$ & $1(8)$ & $1(5)$ & $1(19)$ \\
\hline$\star$ * 2010 only & & & &
\end{tabular}

Table 5. Assessment of time worth according to extent of advance planning - 2010 results

\begin{tabular}{|c|c|c|c|c|c|}
\hline & All & A lot & A little & $\begin{array}{l}\text { Planning in Advance } \\
\text { Very little as I always } \\
\text { use my journey time the } \\
\text { same way }\end{array}$ & $\begin{array}{c}\text { Not at } \\
\text { all }\end{array}$ \\
\hline $\begin{array}{l}\text { I made very worthwhile use of my } \\
\text { time on this train today }\end{array}$ & 30 & 64 & 29 & 31 & 21 \\
\hline & 55 & 32 & 63 & 56 & 53 \\
\hline $\begin{array}{l}\text { My time spent on this train is } \\
\text { wasted time }\end{array}$ & 13 & 3 & 7 & 12 & 22 \\
\hline Not stated & 2 & 1 & 1 & 1 & 4 \\
\hline
\end{tabular}


Table 6. Items individuals had to hand and items individuals used (2004 figures in brackets)

\begin{tabular}{lrrr} 
Carried Items & to hand (\%) & \multicolumn{1}{c}{ used (\%) } & used/to hand \\
\hline Newspaper & $45(79)$ & $32(29)$ & $0.71(0.37)$ \\
Reading book & $36(36)$ & $21(20)$ & $0.59(0.56)$ \\
Text book & $7(7)$ & $3(3)$ & $0.43(0.44)$ \\
Magazine & $12(15)$ & $7(8)$ & $0.53(0.52)$ \\
Paperwork & $21(24)$ & $11(12)$ & $0.51(0.51)$ \\
Games/puzzles & $6(3)$ & $2(1)$ & $0.36(0.41)$ \\
Food/drink & $26(30)$ & $16(19)$ & $0.62(0.6)$ \\
Laptop computer & $11(7)$ & $4(2)$ & $0.32(0.30)$ \\
Netbook * & 2 & 1 & 0.40 \\
Mobile phone & $69(66)$ & $37(24)$ & $0.54(0.36)$ \\
Portable DVD player * & 1 & 0 & 0.43 \\
MP3 player/personal stereo & $22(12)$ & $13(6.4)$ & $0.58(0.56)$ \\
Games console & $1(0)$ & $1(0)$ & $0.45(0.50)$ \\
eBook/iPad * & 2 & 1 & 0.57 \\
Not stated & $5(6)$ & $23(30)$ & \\
\hline * 2010 categories only & & &
\end{tabular}

